\title{
Adherence with COVID-19 Preventive Measures and Associated Factors Among Residents of Shashemane, Central Ethiopia
}

\author{
Paradise valley college \\ Banchiwosen Asefa \\ Addis Ababa education bureau \\ Girum Gebremeskel \\ Dilla University \\ Asefa Washo \\ Paradise valley college \\ Temesgen Muche \\ Dilla University
}

Adane Tesfaye ( $\square$ adanetesfaye2006@gmail.com )

\section{Research Article}

Keywords: Adherence, COVID-19, Practices, Shashemane, Ethiopia

Posted Date: September 21st, 2021

DOI: https://doi.org/10.21203/rs.3.rs-919205/v1

License: @ (i) This work is licensed under a Creative Commons Attribution 4.0 International License. Read Full License 


\section{Abstract}

Introduction:

Covid 19 pandemic can seriously affect African nations because of the weak health care system, crowding, poor hygiene in the cities, and the random mobility of people. Hospital-based interventions are not a good choice for resource-scarce countries which have shortages of hospital beds, ventilators, and oxygen; rather practicing preventive measures at a community level is the best strategy. There is a shortage of evidence about current public adherence with COVID-19 preventive strategies in Ethiopia, therefore this study helps to target health education messages to groups of populations with poor compliance to specific prevention measures, which also contribute to decreasing the magnitude and duration of the pandemic.

Methods:

A Community based cross-sectional study was done on 405 participants selected by systematic random sampling in Shashemane. Data was collected using A pretested structured tool comprising socio-demographic characteristics, knowledge, attitude, and adherence with COVID-19 prevention practice. Participants who practiced $\geq 75 \%$ of the COVID-19 preventive practices were labeled as having "good adherence". Bivariate and multivariable logistic regression was used to determine the associated variables. Odds ratios along with $95 \% \mathrm{Cl}$ were estimated to identify associated factors and a level of statistical significance was decided at $\mathrm{p}$-value less than 0.05 .

Result:

The practice of COVID-19 preventive measures was 19.5\%, (95\% Cl: 15-24.5\%). Having a favorable attitude (AOR = 5, 95\% Cl: 3.3-8.41), having good knowledge of the disease $(\mathrm{AOR}=3,95 \% \mathrm{Cl}$ : $2.74-9.3)$ and educational status (Diploma and above) ( $\mathrm{AOR}=5.5,95 \% \mathrm{Cl}$ : $2-$ 9.39) were significantly associated factors with the practice of COVID-19 preventive measures.

Conclusion:

The Adherence to COVID-19 preventive practices was very low, educational status above Diploma, good knowledge, and Favorable attitude were the factors positively and independently associated with good adherence to Covid-19 prevention practices. Behavioral change communication and Strict government law and implementing it are highly required.

\section{Introduction}

COVID-19 infection is primarily transmitted by the direct mucus contact with the breath, ingestion, salivary droplet of an infected individual that can live on hands, surfaces, or objects [1-3]. The rapid worldwide spread of COVID-19 forced the World health organization to declare the COVID-19 pandemic as a public health emergency of international importance by January 2020. This kind of decision is made when an incident with major public health implications crosses the boundaries of the nation's initially affected, requiring immediate international action [4]. Up to September 10,2021, there have been 224,383,843 worldwide confirmed cases of COVID-19 and 4,625,768 deaths. [5], Out of which 7,993,715 Cases are from Africa with 202,042 Deaths [6] and In Ethiopia, there have been 320,453 confirmed cases with 4,857 deaths [7].

WHO strictly recommended COVID-19 prevention approaches such as keeping physical distance, wearing a face mask, avoiding going to crowded places, hand washing, making rooms ventilated, and covering nose and mouth while sneezing or coughing, avoiding closer contact with animals and suspected area with coronavirus infections, and avoiding consumption and handling of raw meat to prevent cross-contamination [8-11]

Experts believed Covid 19 pandemic can seriously affect African nations because of the weak health care system, crowding, poor hygiene in the cities, and the random mobility of people can make the epidemic out of control. [12, 13]. Global experts and African governments have articulated their concern regarding the transmission of COVID-19 and projected that over two million deaths might happen in sub-Saharan Africa if immediate action is not taken [14].

The pandemic is challenging both for developed and developing nation's healthcare system, social, economic, and psychological wellbeing of humanity. For countries with hospitals and clinics that were already overburdened before covid-19, practicing preventive measures at a community level is the best strategy. Hospital-based interventions are not a good choice for resource-scarce countries which have limited personal protective devices, shortages of hospital beds, ventilators, and oxygen. [15, 16]. 
Ethiopia has an underprivileged public health system and sectors, limited infrastructure, inadequate number of hospitals, little capacity for tracing, diagnosing, isolation, and management of cases [17], therefore more focus should be given on prevention strategies.

There is a shortage of evidence about current public adherence with COVID-19 preventive strategies in Ethiopia, therefore this study helps to target health education messages to groups of populations with poor compliance to specific prevention measures, which also contribute to decreasing the magnitude and duration of the pandemic

\section{Methods And Materials}

\section{Study Area}

The study was done in Shashamane Town, one of the towns in the Oromia national Region, in west Arsi zone. Shashamane is located at south of Addis Ababa about $250 \mathrm{~km}$. The town lies roughly $7008^{\prime} 51^{\prime \prime} \mathrm{N}$ to $7018^{\prime} 19^{\prime \prime} \mathrm{N}$ latitude and $38032^{\prime} 43^{\prime \prime} \mathrm{E} 38041^{\prime} 07^{\prime \prime} \mathrm{E}$ longitude. The town is located at the upper greatest east African rift valley. It has a sub-tropical middle land climatic zone. Agriculture is the likelihood of the majority of the study population.

\section{Sample size determination}

The single population proportion formula was used to calculate the sample size by considering a study conducted at Diredawa which revealed covid 19 prevention practice of $40.7 \%$ (18) and using 95\% confidence interval, 0.05 margin of error, and a 10\% non-response rate. The final sample size was 407.

\section{Sampling Procedure}

From the seven sub-cities of Shashemane, three were selected using a simple random sampling method, and then 407 participants were selected by systematic random sampling technique, using the sampling frame of households from the 3 sub-cities. The total number of households was proportionally allocated to ( Abosto, bulchana and Arada sub cities) based on the number of households within each of them. Any individual who was a resident of the area, age over 18 years old, and who are healthy were included. Study variables include Age of the Participant, Sex, marital status Occupation, Educational status, Average monthly Income, Family size, Source of information.

\section{Instrument and Outcome measurement}

We developed the questionnaire based on a literature review and adapted it from WHO resources. It includes sociodemographic information, behavioral characteristics, knowledge, attitude, and practices towards COVID-19 prevention actions (19-21,24). The attitude variable was converted into a dummy variable of unfavorable and favorable attitudes. For each item participants who answered (a) strongly disagree, (b) disagree, or (c) neutral were combined into one group and categorized as an unfavorable attitude" and those participants who responded (d) agree or (e) strongly agree were labeled as having "favorable attitude". Overall, the attitude was generated from the dummy variables created from the Likert scale items and those participants who had "favorable attitude" for all the attitude questions were grouped as "favorable attitude" and all else were categorized as "unfavorable attitude". (24) Regarding the participants' adherence, those who practiced $\geq 75 \%$ of the COVID-19 preventive practices were labeled as having "good adherence"

Also, there were 12 (twelve) knowledge measuring questions, in which each question scored 0 and $1(0=$ No, $1=$ Yes). We considered those study participants who scored below the mean value out of twelve questions as they have poor knowledge and those who scored a mean and above the mean value as they have good knowledge (18).

\section{Data collection, management, and analysis}

Socio-demographic data was cleaned manually and entered into the computer using Epidata version 3.3 and statistical analysis was made using SPSS version 25, whereas, Descriptive summary (Frequency distribution, proportion, mean \& standard deviation) was used to summarize the variable. Continuous variables like age and income were first transformed into categorical variables before they were analyzed. First, the frequency of all the variables in the questionnaire was determined. Bivariate \& multivariable logistic regression was done to assess the association of factors with Adherence to covid-19 prevention measures, by calculating odds ratios, their $95 \%$ confidence limits, and P-value less than or equal to 0.05 was taken as statistically significant. Important variables were entered and analyzed using multivariable logistic regressions to control for confounding variables. All the assumptions of regression analysis (model adequacy and multi-co linearity of independent variables) were checked to be satisfied using appropriate methods. 


\section{Data quality control}

Data quality control was ensured by conducting a pretest on about $5 \%$ of the sample size that was randomly selected from participants out of the study population and then the data were checked for internal consistency and modifications were made accordingly.

\section{Ethical Considerations}

An ethical Approval Letter was taken from Paradise college. Informed consent was obtained from each respondent and they were told to have the full right to give up the interview any time he/she wishes. The purpose of the research was well communicated and never exposed the privacy of the participants. A consent paper was prepared and participants gave consent before the data collection started.

\section{Results}

\section{Socio-Demographic Characteristics}

Out of 407 study participants initially sampled in the study, 405 have participated, making a response rate of $99 \%$. The mean ( \pm SD) age of the study participants was $(32.5( \pm 14.4)$ years with a minimum age of 18 years and maximum age of 64 years. About $50 \%$ of participants are young adults (age 18-35 years),22\% are middle-aged adults (ages $36-55$ years), and the rest $28 \%$ are older adults. (Table 1)

Table 1: Socio-economic and demographic characteristics of Study Participants in Shashemane, Central Ethiopia, 2021 ( $n=405)$ 


\begin{tabular}{|c|c|c|c|}
\hline \multicolumn{2}{|l|}{ Variable } & Frequency & Percent \\
\hline \multicolumn{2}{|c|}{ Age in years $18-35$} & 201 & 49.6 \\
\hline \multicolumn{2}{|c|}{$36-55$} & 89 & 22 \\
\hline \multicolumn{2}{|c|}{$>56$} & 115 & 28.4 \\
\hline \multirow[t]{2}{*}{ Sex } & Male & 242 & 59.7 \\
\hline & & 163 & 40.3 \\
\hline Marital status & Married & 293 & 72 \\
\hline \multicolumn{2}{|c|}{ Single } & 87 & 21.4 \\
\hline \multicolumn{2}{|c|}{ Widowed } & 14 & 3.4 \\
\hline \multicolumn{2}{|c|}{ Separated } & 11 & 2.7 \\
\hline \multicolumn{2}{|l|}{ Family size } & 153 & 37.8 \\
\hline \multicolumn{2}{|c|}{$\geq 5$} & 252 & 62.2 \\
\hline \multirow[t]{6}{*}{ Occupational } & Government org. & 108 & 26.6 \\
\hline & Marchant & 103 & 25.4 \\
\hline & House wife & 52 & 12.8 \\
\hline & Private org. & 66 & 16.3 \\
\hline & Student & 37 & 9 \\
\hline & Other & 39 & 9.6 \\
\hline \multicolumn{2}{|c|}{ Educational status No formal education } & 120 & 29.6 \\
\hline & Can read and write & 100 & 24.6 \\
\hline & Primary school & 79 & 19.5 \\
\hline & Secondary school & 59 & 14.5 \\
\hline & Diploma\&+ & 46 & 11.3 \\
\hline \multicolumn{4}{|c|}{ Average Household Income per month } \\
\hline \multicolumn{2}{|c|}{$<5000$ ETB } & 270 & 66.7 \\
\hline \multicolumn{2}{|c|}{ 5000-10,000 ЕТВ } & 116 & 28.6 \\
\hline \multicolumn{2}{|c|}{$>10,000 \mathrm{ETB}$} & 19 & 4.7 \\
\hline
\end{tabular}

\section{Knowledge About COVID-19}

Only about $29 \%$ of the participants know as Asymptomatic person could transmit COVID-19, about $36 \%$ of the participants know as stuffy nose, runny nose, and sneezing are less common in persons infected with the COVID-19 virus. (Figure-1)

\section{Attitude of Participants Towards COVID-19}

$57.7 \%$ of the participants have unfavorable attitude towards Covid-19. $52.3 \%$ of the participants believed that hand washing can prevent or reduce transmission of COVID-19. (Table 2)

Table 2: Attitude of Study Participants About COVID-19 Prevention Measures in Shashemane, Central Ethiopia, 2021 ( $n=405)$ 


\begin{tabular}{|llc|}
\hline Item & Favorable \% Unfavorable & $\%$ \\
\hline Do you think that COVID-19 disease is dangerous? & 23.6 & 76.4 \\
\hline Do you believe that hand washing can prevent/reduce transmission? & 52.3 & 47.7 \\
\hline Do you think that wearing a mask will prevent/decrease transmission? & 51.7 & 48.3 \\
\hline Do you think that using alcohol/sanitizers decrease transmission? & 42.4 & 57.6 \\
\hline Do you think to stay at home/avoid going to crowded places prevent transmission? & 52.3 & 47.7 \\
\hline Do you think that keeping social distance will prevent transmission? & 39.8 & 61.2 \\
\hline Do you agree that COVID-19 will finally be successfully controlled? & 65.4 & 34.5 \\
\hline Do you think eating wild animals will transmit the disease? & 29.7 & 70.3 \\
\hline Do you think Ethiopia can win the battle against the CovID-19 virus? & 32.5 \\
\hline
\end{tabular}

\section{Adherence with COVID-19 Preventive practices}

Only $19.5 \%$, (95\% Cl: $15-24.5)$ of the participants had a good practice on prevention methods of COVID-19. About $48 \%$ of the participants wear face Mask consistently when they go out of home (Figure-2)

\section{Factors Associated with Adherence of COVID-19 Prevention Practices}

After running the multivariable analysis; attitude, knowledge, and Educational Status are associated with COVID-19 preventive practices adherence. The odds of Adherence with COVID-19 preventive measures were 5 times (AOR = 5, 95\% Cl: 3.3 - 8.41) higher among participants whose attitude is favorable as compared to those who have unfavorable attitudes. The odds of Adherence with COVID-19 preventive measures were 3 times ( $\mathrm{AOR}=3,95 \% \mathrm{Cl}$ : 2.74-9.3) higher among participants who had good knowledge of the disease as compared to those who have poor Knowledge. The odds of Adherence with COVID-19 preventive measures were about 5.5 times higher (AOR $=5.5,95 \%$ Cl: $2-9.39$ ) among participants whose educational status is Diploma and above as compared to those who have no formal education.

Table-3: Factors associated with Adherence with COVID-19 Preventive Measures Among Residents of Shashemane, Central Ethiopia September 2021, $(n=405)$. 


\begin{tabular}{|c|c|c|c|c|c|}
\hline \multirow[t]{2}{*}{ Variables } & & \multicolumn{2}{|c|}{ Adherence } & \multirow{2}{*}{$\begin{array}{c}\text { COR } \\
(95 \% \text { CI })\end{array}$} & \multirow{2}{*}{$\begin{array}{l}\text { AOR } \\
(95 \% C I)\end{array}$} \\
\hline & & $\begin{array}{c}\text { Good } \\
\text { Adherence } \\
\text { Yes } \\
\end{array}$ & No & & \\
\hline \multirow[t]{3}{*}{ Age } & $18-35$ & $15(7.4 \%)$ & $186(92.6 \%)$ & 1 & 1 \\
\hline & $36-55$ & $22(24.7 \%)$ & $67(75.3 \%)$ & $4.3(2.4-8.9)$ & $1.8(0.3-6.9)$ \\
\hline & $56 \&$ above & $42(36.5 \%)$ & $73(63.5 \%)$ & 7 (4.4-13.87) & $4(1.75-16)$ \\
\hline \multirow[t]{5}{*}{ Educational status } & No formal-edu & $5(4 \%)$ & $115(96 \%)$ & 1 & 1 \\
\hline & Read \& write & $13(13 \%)$ & $87(87 \%)$ & $3.43(2.2-7.6)$ & $2.8(1.5-11)$ \\
\hline & Elementary & $14(17 \%)$ & $65(82 \%)$ & $4.95(2.7-8,9)$ & $3.5(2-8.35)$ \\
\hline & High school & $18(30.5 \%)$ & $41(69.5 \%)$ & $10(3.7-18)$ & $4(2.8-7)$ \\
\hline & Diploma\&+ & $29(63 \%)$ & $17(33 \%)$ & $39(18-42.48)$ & $5.5(2-9.39) * *$ \\
\hline \multirow[t]{2}{*}{ Sex } & Female & $51(31 \%)$ & $112(69 \%)$ & $3.4(1.8-5.45)$ & $1.7(1.28-6.2)$ \\
\hline & Male & $28(11 \%)$ & $214(89 \%)$ & 1 & 1 \\
\hline \multirow[t]{6}{*}{ Occupation } & Government & $32(29 \%)$ & $76(71 \%)$ & 1 & 1 \\
\hline & Marchant & $22(21 \%)$ & $81(79 \%)$ & $0.64(0.02-0.87)$ & $0.5(0.2-0.87)^{*}$ \\
\hline & House wife & $4(7.6 \%)$ & $48(92.4 \%)$ & $0.2(0.04-3.27)$ & $0.18(0.06-0.45)$ \\
\hline & Private org & $11(16.6 \%)$ & $55(83.4 \%)$ & $0.475(024-0.74)$ & $0.3(0.17-0.56)$ \\
\hline & Student & $8(21 \%)$ & $29(79 \%)$ & $0.65(0.32-0.94)$ & $0.3(0.2-0.67)$ \\
\hline & Other" & $2(5 \%)$ & $37(95 \%)$ & $0.12(0.08-0.3)$ & $0.06(0.6-5.7)$ \\
\hline \multirow[t]{2}{*}{ Knowledge } & Good & $57(7.2 \%)$ & $101(92.8 \%)$ & $5.7(3.8-8.63)$ & $3(2.74-9.3)^{* * *}$ \\
\hline & Poor & $22(8.9 \%)$ & $225(91.1 \%)$ & 1 & 1 \\
\hline \multirow[t]{2}{*}{ Attitude } & Unfavorable & $17(\%)$ & $217(\%)$ & $7.2(1.84-10.89)$ & $5(3.3-8.41)^{* * *}$ \\
\hline & Favorable & $62(\%)$ & $109(\%)$ & 1 & 1 \\
\hline
\end{tabular}

* Significant at $P=<0.05$ * * Significant at $P=<0.002$, * * Significant at $P=<0.001$, OR $=$ Odd ratio, AOR=Adjusted odd ratio, Cl= Confidence interval

\section{Discussion}

Adherence to the preventive measures is the most important intervention for covid-19 throughout the world and most importantly in resource scare countries, the study investigated this and comes up with a very low level of adherence with the practice of COVID-19 prevention measures, only $19.5 \%$, with (95\% Cl: 15-24.5). This magnitude of good practice of Covid preventive measures was lower than studies conducted in Diredawa (40.7\% (18), Gonder (51\%) (22), and south Ethiopia 20\% (23) and higher than a study conducted at Dirashe district (12.3\%) (24). When we compare it with other African countries it is much lower than cross-sectional studies conducted in Nigeria 41.6\% (25), Cameron (60.8\%) (26), Burkina Faso (39\%) (27), and A nationwide cross-sectional Survey at Ugandan( 85.3\%) (28). The difference could be attributed to the period the studies were conducted, the type of study participants, and the different levels of awareness creation and other interventions done at the study areas.

We have found that educational status positively impacts the practice of our study participants. Study participants who have a diploma and above had a good level of practice to prevent the pandemic compared with those who have no formal education. This was in agreement with a study finding from A Community-Based Cross-Sectional Study conducted at Gedeo zone (29), Debre Tabor Town Northwest Ethiopia (30), northern Thailand (31), Nigeria (32), and Iran (33). This might be because more educated people can access information from different sources like the internet easily and discuss openly, usually more educated are working at different types of organizations where there is strict rule and provision of different Covid-19 prevention materials and information. 
Participants who had good knowledge on the mode of transmission and prevention mechanisms of COVID-19 had a better practice of precautionary measures ( $p$ value $<0.00$ ), and this result is consistent with researches conducted at Dire Dawa residents (18), Amhara region (34) and Addis Ababa (35). Knowledge is the main modifier of attitudes that can lead to a better practice of COVID-19 preventive measures, one cannot have a good practice without adequate knowledge of the disease, what to do and what not to do. Knowledge about COVID-19 disease nature, signs and symptoms, mechanisms and modes of spread, and how to avoid the infection will increase the prevention practice of individuals.

This study revealed that the Attitude of participants is strongly associated with COVID-19 preventive measures. Favorable attitudes towards COVID-19 preventive approaches were significantly associated with good adherence towards COVID-19 prevention measures. This finding is in line with other studies conducted in Gonder (22), Jimma (36) Addis Ababa, Ethiopia (37), However, Attitude is not permanent, enhancing a positive attitude towards preventive practice should be performed to make it sustainable among the population.

The findings of knowledge, attitude, and practices are alarming, we cannot change attitude and practice only by giving information a strong health education targeting behavioral change by different teaching methods and materials should be strengthened, Strict government rules and implementing it is required. The impact of the pandemic is to all countries but developing countries like ours can be massively affected, Human day-to-day activities including the economy and health care systems will be more affected unless this poor adherence to covid-19 prevention measures is improved $(38,39)$.

\section{Conclusion}

Adherence to COVID-19 preventive practices was very low, educational status above Diploma good knowledge and Favorable attitude were the factors positively and independently associated with good adherence of Covid-19 prevention practices. Behavioral change communication and Strict government law and implementing it are highly required.

\section{Declarations}

\section{Data Sharing Statement}

The datasets used or analyzed during the current study are available from the corresponding author on reasonable request.

\section{Ethical Approval and Consent to Participate}

The study was conducted in accordance with the Declaration of Helsinki. Ethical approval was received from Paradise Valley College. Verbal consent was obtained from each respondent before actual data collection. Issues of confidentiality were maintained by removing any identifiers from the questionnaire. The participants were informed of their right to participate and leave the study at any point in time.

\section{Acknowledgments}

We would like to thank Paradise Valley College for funding this research.

\section{Author Contributions}

AT was involved in the conception of the study. All authors made a significant contribution to the work reported, on study design, execution, analysis, and interpretation, took part in drafting, revising, and critically reviewing the article; gave final approval of the version to be published; have agreed on the journal to which the article has been submitted; and agree to be accountable for all aspects of the work.

\section{Disclosure}

The authors report no conflicts of interest for this work.

\section{Abbreviations}

AOR- adjusted odds ratio; COVID-19- coronavirus 2019;; SPSS, Statistical Package for Social Science; US, United States of America; WHO, World Health Organization. 


\section{References}

1. Meng L, Hua F, Bian Z. Coronavirus Disease 2019 (COVID-19): emerging and future challenges for dental and oral medicine. J Dent Res. 2020 May 12;99(5):481-7.

2. Peng X, Xu X, Li Y, Cheng L, Zhou X, Ren B. Transmission routes of 2019-nCoV and controls in dental practice. Int J Oral Sci. 2020 Mar 3;12(1):9.

3. Zhu N, Zhang D, Wang W, et al. A novel coronavirus from patients with pneumonia in China, 2019. N Engl J Med. 2020;382: 727-3.

4. World Health Organization. Coronavirus disease 2019 (COVID-19). Situational Report-37. Disponível em

5. WHO, 2021, https://www.worldometers.info/coronavirus/

6. African CDC, 2021, https://africacdc.org/covid-19/

7. Ethiopia: WHO Coronavirus Disease (COVID-19) Dashboard https://covid19.who.int/region/afro/country/et

8. World Health Organization. Coronavirus disease (COVID-19) advice for the public; 2020. Avalable from:

https://www.who.int/emergencies/diseases/novel-coronavirus-2019/advice-for-public. Accessed January23, 2021

9. Brown A, Horton R. A planetary health perspective on COVID-19: a call for papers. Lancet. 2020;395(10230):1099. doi:10.1016/S0140-6736(20)30742-X

10. Chiang C, El Sony A. Tackling the threat of COVID-19 in Africa: an urgent need for practical planning. Int j Tuberculosis Lung Disease. 2020;24.

11. Balachandar V, Mahalaxmi I, Kaavya J, et al. COVID-19: emerging protective measures. Eur Rev Med Pharmacol Sci. 2020;24 (6):3422-3425. doi:10.26355/eurrev_202003_20713

12. Maclean R Africa braces for coronavirus, but slowly. The New York Times; 2020. Avalable from: https://scholar.google.com/scholar? $\mathrm{hl}=\mathrm{en} \approx \mathrm{sdt}=0 \% 2 \mathrm{C}$ \&q=11.\%09Maclean+R.+Africa+braces+for+coronavirus\%2C+but+slowly.+The+New+York+Times.+2020.+\&btnG=.

13. Jump up to a b c d "African Countries respond quickly to spread of COVID-19". Avalable from: NPR.org.

14. Walker PG, Whittaker C, Watson OJ, et al. The impact of COVID-19 and strategies for mitigation and suppression in low-and middleincome countries. Science. 2020; eabc0035. doi:10.1126/science.abc0035

15. Bong CL, Brasher C, Chikumba E, McDougall R, Mellin-Olsen J, Enright A. The COVID-19 pandemic: effects on low and middle-income countries. Anesth Analg. 2020;131:86-92. doi:10.12 13/ANE.0000000000004846

16. McMahon DE, Peters GA, Ivers LC, Freeman EE (2020) Global resource shortages during COVID-19: Bad news for low-income countries. PLoS Negl Trop Dis 14(7): e0008412. https://doi.org/10.1371/journal.pntd.0008412

17. Woldemichael, A., Takian, A., Akbari Sari, A., \& Olyaeemanesh, A. (2019). Availability and inequality in accessibility of health centrebased primary healthcare in Ethiopia. PloS one, 14(3), e0213896. https://doi.org/10.1371/journal.pone.0213896

18. Amsalu, B., Guta, A., Seyoum, Z., Kassie, N., Sema, A., Dejene, W., Fikadu Woldemedhen, Y., Kasahun, M., Sintayehu, Y., \& Belay, Y. (2021). Practice of COVID-19 Prevention Measures and Associated Factors Among Residents of Dire Dawa City, Eastern Ethiopia: Community-Based Study. Journal of multidisciplinary healthcare, 14, 219-228. https://doi.org/10.2147/JMDH.S292409

19. Kebede Y, Yitayih Y, Birhanu Z, Mekonen S, Ambelu A (2020) Knowledge, perceptions and preventive practices towards COVID-19 early in the outbreak among Jimma university medical center visitors, Southwest Ethiopia. PLoS ONE 15(5): e0233744. https://doi.org/10.1371/journal.pone.0233744

20. World Health Organization (WHO). Risk Communication and Community Engagement (RCCE) Action Plan Guidance COVID-19 Preparedness and Response. 16 March 2020. https://www.who.int/docs/default-source/coronaviruse/covid19-rcce-guidance-finalbrand.pdf

21. Geldsetzer P. Knowledge and Perceptions of COVID-19 Among the General Public in the United States and the United Kingdom: A Cross-sectional Online Survey. Ann Intern Med. 2020; https://doi.org/10.7326/M20-0912

22. Azene ZN, Merid MW, Muluneh AG, Geberu DM, Kassa GM, Yenit MK, et al. (2020) Adherence towards COVID-19 mitigation measures and its associated factors among Gondar City residents: A community-based cross-sectional study in Northwest Ethiopia. PLoS ONE 15(12): e0244265. https://doi.org/10.1371/journal.pone.0244265

23. Mola S, Aweke Z, Jemal B, et al. Magnitude and associated factors for attitude and practice of Southern Ethiopian residents toward COVID-19 and its preventions: a community-based cross-sectional study. 2020. doi:10.21203/rs.3.rs-36120/v1

24. Bante A, Mersha A, Tesfaye A, Tsegaye B, Shibiru S, Ayele G, Girma M. Adherence with COVID-19 Preventive Measures and Associated Factors Among Residents of Dirashe District, Southern Ethiopia. Patient Prefer Adherence. 2021;15:237-249, 
https://doi.org/10.2147/PPA.S293647

25. Elizabeth Uzoamaka Nwonwu et al. Knowledge and preventive practice to COVID-19 among household heads in Enugu metropolis, South-East Nigeria. Pan African Medical Journal. 2020;63(63). 10.11604/pamj.2020.37.63.23986

26. Ngwewondo A, Nkengazong L, Ambe LA, Ebogo JT, Mba FM, Goni HO, et al. (2020) Knowledge, attitudes, practices of/towards COVID 19 preventive measures and symptoms: A cross-sectional study during the exponential rise of the outbreak in Cameroon. PLoS Negl Trop Dis 14(9): e0008700. https://doi.org/10.1371/journal.pntd.0008700

27. Firehiwot Workneh, Dongqing Wang Yemane Berhane, et al, Knowledge and Practice Related to COVID-19 and Mental Health among Adults in Sub-Saharan Africa, DOI: https://doi.org/10.4269/ajtmh.21-0219, V = 105: Issue 2

28. Robinson Ssebuufu, Franck Katembo Sikakulya, Simon Mambo Binezero, Lucien Wasingya, 2020, Awareness, knowledge, attitude and practice towards measures for prevention of the spread of COVID-19 in the Ugandans: A nationwide online cross-sectional Survey, doi: https://doi.org/10.1101/2020.05.05.20092247

29. Mola S, Aweke Z, Jemal B, Hussen R, Hailu S, Neme D, Mulugeta H, Zemedkun A. Magnitude and Associated Factors for Attitude and Practice Toward COVID-19 and Its Prevention Among the Residents of Gedeo Zone, Southern Ethiopia: A Community-Based CrossSectional Study. Risk Manag Healthc Policy. 2021;14:253-262. https://doi.org/10.2147/RMHP.S277904

30. yele, A.D., Mihretie, G.N., Belay, H.G. et al. Knowledge and practice to prevent COVID-19 and its associated factors among pregnant women in Debre Tabor Town Northwest Ethiopia, a community-based cross-sectional study. BMC Pregnancy Childbirth 21,397 (2021). https://doi.org/10.1186/s12884-021-03877-4

31. Srichan P, Apidechkul T, Tamornpark R, Yeemard F, Khunthason S, Kitchanapaiboon S, Wongnuch P, Wongphaet A, Upala P. Knowledge, attitudes and preparedness to respond to COVID-19 among the border population of northern Thailand in the early period of the pandemic: a cross-sectional study. WHO South-East Asia J Public Health 2020;9:118-25

32. Erfani A, Shahriarirad R, Ranjbar K, Mirahmadizadeh A, Moghadami M. Knowledge, attitude and practice toward the novel coronavirus (COVID-19) outbreak: a population-based survey in Iran. Bull World Health Organ. 2020;30(10.2471).

33. Nwafor JI, Aniukwu JK, Anozie BO, Ikeotuonye AC. Knowledge and practice of preventive measures against COVID-19 infection among pregnant women in a low-resource African setting. medRxiv. 2020.

34. Asemahagn MA. Factors determining the knowledge and prevention practice of healthcare workers towards COVID-19 in Amhara region, Ethiopia: a cross-sectional survey. Trop Med Health. 2020;48(1):1. doi:10.1186/s41182-020-00254-3

35. Defar A, Molla G, Abdella S, Tessema M, Ahmed M, Tadele A, et al. (2021) Knowledge, practice and associated factors towards the prevention of COVID-19 among high-risk groups: A cross-sectional study in Addis Ababa, Ethiopia. PLoS ONE 16(3): e0248420. https://doi.org/ 10.1371/journal.pone.024842

36. Assefa D, Melaku T, Bayisa B, Alemu S. COVID-19 Pandemic and its Implication on Hand Hygiene Status by Alcohol-based Hand Sanitizers Among Healthcare Workers in Jimma University Medical Center, Ethiopia. 2020

37. Desalegn Z, Deyessa N, Teka B, Shiferaw W, Hailemariam D, Addissie A, et al. (2021) COVID-19 and the public response: Knowledge, attitude and practice of the public in mitigating the pandemic in Addis Ababa, Ethiopia. PLoS ONE 16(1): e0244780. https://doi.org/10.1371/journal.pone.0244780

38. Ahmad T, Haroon MB, Hui J, Hui J. Coronavirus disease 2019 (COVID-19) pandemic and economic impact. Pak J Med Sci. 2020;36(COVID19-S4):S73. doi:10.12669/pjms.36.COVID19-S4.2638

39. Tandon A, Roubal T, McDonald L, et al. Economic Impact of COVID-19: Implications for Health Financing in Asia and Pacific. World Bank; 2020

\section{Figures}




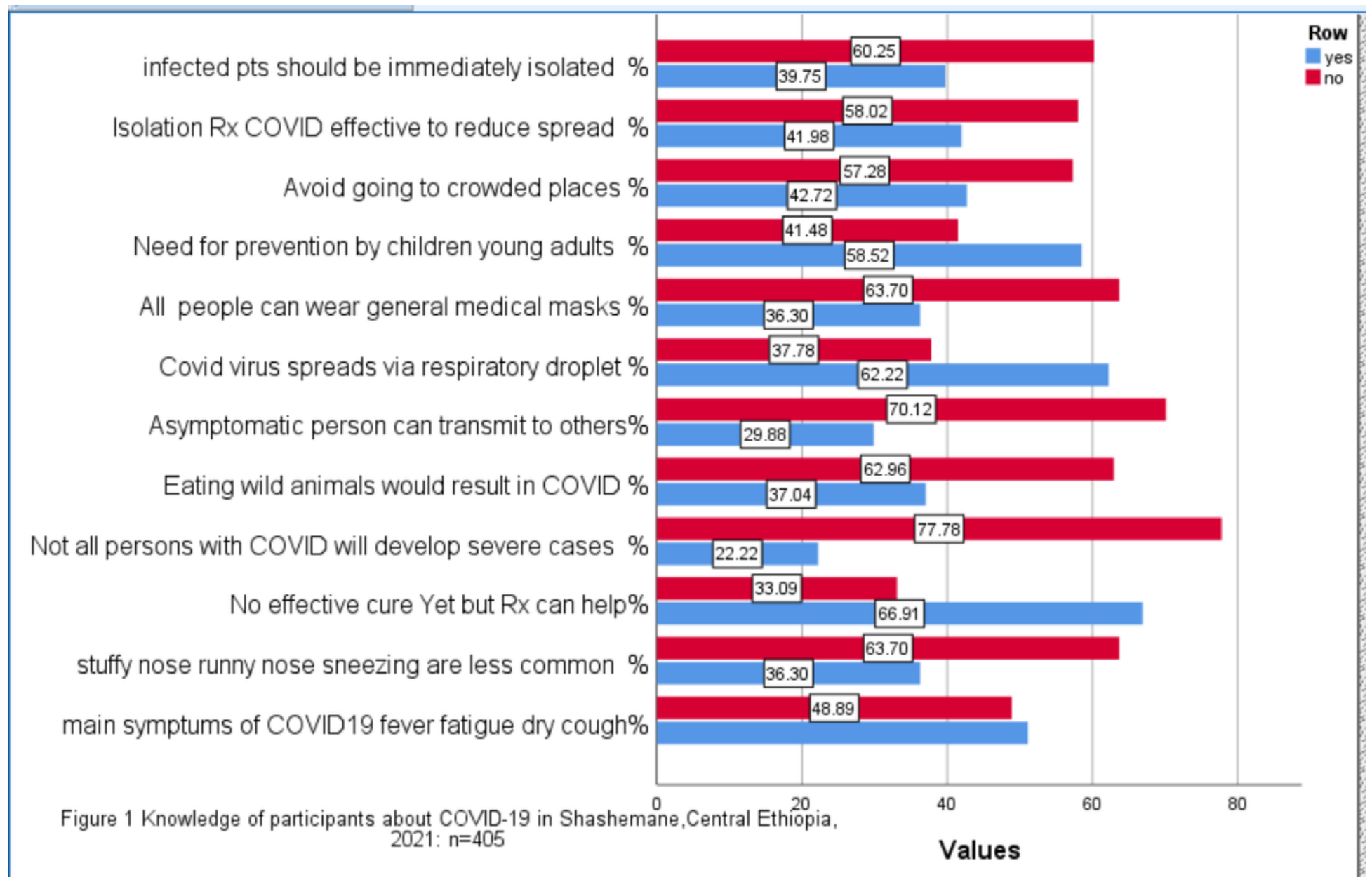

Figure 1

Knowledge of participants about COVID-19 in Shashemane, Central Ethiopia, 2021: n=405 
Practice of COVID-19 prevention measures

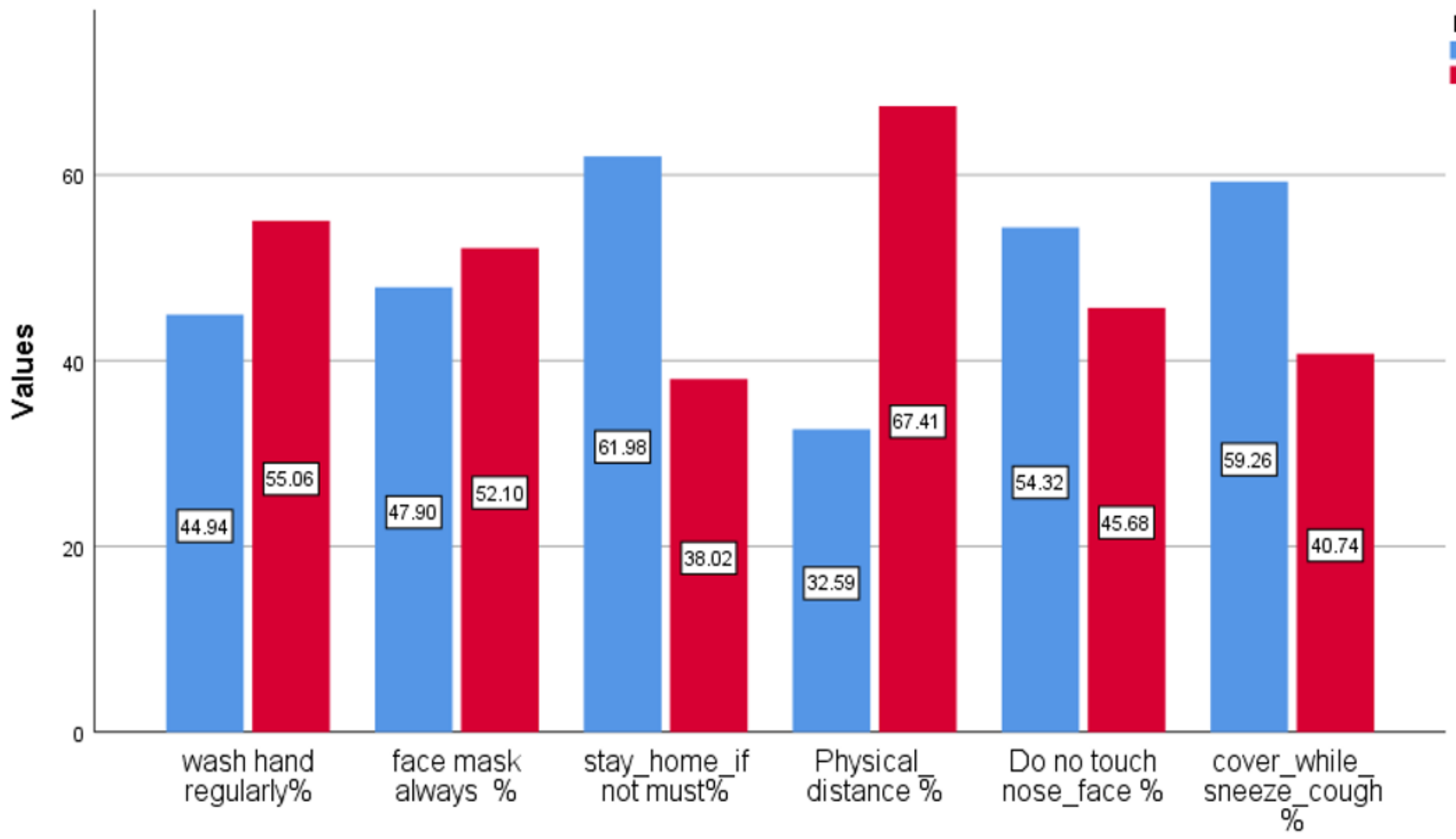

Figure 2 Practice of COVID-19 prevention measures among Resedents of Shashemane, Central Ethiopia, 2021

Figure 2

Practice of COVID-19 prevention measures among Residents of Shashemane, Central Ethiopia, 2021 